\title{
The Feasibility and Effectiveness of Android-based Augmented Reality Learning Media on Mechanical Wave Material
}

\author{
Ai Nurlaela ${ }^{1}$, Taufiq Al Farizi ${ }^{2}$, Mayuriko Olivia Pertiwi ${ }^{3}$ \\ \{ai.nurlaela@uinjkt.ac.id ${ }^{1}$, taufiq.farizi@uinjkt.ac.id ${ }^{2}, \underline{\left.\text { mayuriko.pertiwi14@mhs.uinjkt.ac.id }{ }^{3}\right\}}$ \\ ${ }^{1,2,3}$ UIN Syarif Hidayatullah Jakarta, Indonesia
}

\begin{abstract}
Learning media that are commonly used in schools are still conventional so they have several weaknesses in the transfer of learning information. Augmented Reality (AR) can be used as alternative learning media. This study aims to determine the level of feasibility and effectiveness of mechanical wave AR media in learning. The research method used is the type of Jan van den Akker development research, which has steps such as preliminary research, prototyping stage, summative evaluation, and systematic reflection and documentation. The sample was selected using a purposive sampling technique. Mechanical wave AR media was declared very feasible by learning media experts, learning design experts, and material experts with an average value of $91.7 \%$, as well as assessment by students of $88 \%$. The effectiveness of the media is shown by the average completeness of student learning outcomes by $70 \%$ and is very effective based on the physics teacher's assessment of $94 \%$.
\end{abstract}

Keywords. Android, augmented reality, development research, effective, feasible, learning media, mechanical waves.

\section{Introduction}

The use of media will increase the effectiveness of the learning process. Learning media in the teaching and learning process can arouse interest, arouse motivation, and stimulate learning activities. According to Evgeny Aleksandrov and Anastasia Levitskaya [1], the use of media in learning can stimulate the development of social and professional competence.

Conventional learning methods that use media such as blackboards and drawings in books certainly have limitations to provide more visualizations that are tangible to students. Conventional schoolbooks do not represent actual sources of knowledge, so that electronic learning media covers the shortcomings of old media [2]. On the other hand, the use of digital media contributes to the improvement of teaching [3].

$\mathrm{AR}$ is one alternative media that can be used as an appropriate visual media for students. AR technology has been widely implemented in education [4]. Students can see physical phenomena in three dimensions (3D) through AR media. 3D media extends 2D representation because it can animate pictorial content and is a very effective method for handling excessive information such as text [5]. AR technology allows the addition of virtual objects into real environments that make users interact more real-time. Mariana Pohlmann and Fabio Pinto da Silva [6] argue that technology increases learning opportunities more effectively, given that visualization and interaction help students. Learning media using AR attract students' interest when learning because it is more interactive. Interactive media can arouse students' interest and motivation in finding information independently, so students will get information that is 
more meaningful and improve their memory. Students prefer to use new media (AR) rather than using conventional teaching materials, students show interest and interact quickly and there is coordination between eyes and hands [7].

AR media has a good contribution value in the field of education. Since its introduction, AR has proven to have good potential in a more active, effective and meaningful learning process [8]. According to Su Cai, et. al. [9], AR greatly stimulates students' interest in learning and increases their learning activities. AR technology can minimize the use of practical tools that are vulnerable to equipment damage and facilitate the learning process wherever and whenever. Learning media using AR saves time and resources [10]. Julio Cabero Almenara, et. al. [11] said that AR gets more relevance in education because of its ease of use and availability of devices.

Mechanical waves are one of the abstract concepts in physics; we need imagination to understand them, so we need a media that can visualize the wave material more real so that the process of understanding concepts is easier. Mechanical waves are an important topic in most introductory physics curricula at the university level and many fields of physics depend on a strong understanding of mechanical waves [12]. Interviews with teachers in the preliminary research provide information that students have problems in understanding and imagining wave material in learning, one of them is due to the limitations of the existing visual media, so that AR can be used as an alternative learning media.

\section{Methods}

\subsection{Research and Development Procedures}

There are two models in development research, namely validation studies and development studies [13]. We use development studies models that aim to produce media products that can solve learning problems using existing knowledge. The steps of the development studies research model according to Akker et. al, including preliminary research, prototyping stage, summative evaluation, and systematic reflection and documentation.

\subsubsection{Preliminary Research}

The steps at this stage are the literature study and field survey. Literature study intended to look for problems related to learning in schools and the lack of existing media. Field survey intended to complement and strengthen the findings in the study of literature. The survey was conducted at a state high school in South Tangerang, which consisted of interviews with physics teachers and distributed questionnaires to 326 students.

\subsubsection{Prototyping Stage}

The making and improvement of product prototypes as a media for solving problems obtained after finding problems in the learning process at the preliminary research. The prototyping stage consists of designing the guidelines, optimizing prototypes, formative evaluations, and revisions.

The design of the guidelines is done by selecting teaching material, designing the concept of AR media design, and designing the media software. Optimization of design prototypes is done by selecting software and making AR media. Formative evaluation is the stage of product evaluation that has been made. Formative evaluation flow is illustrated in Figure. 1. 


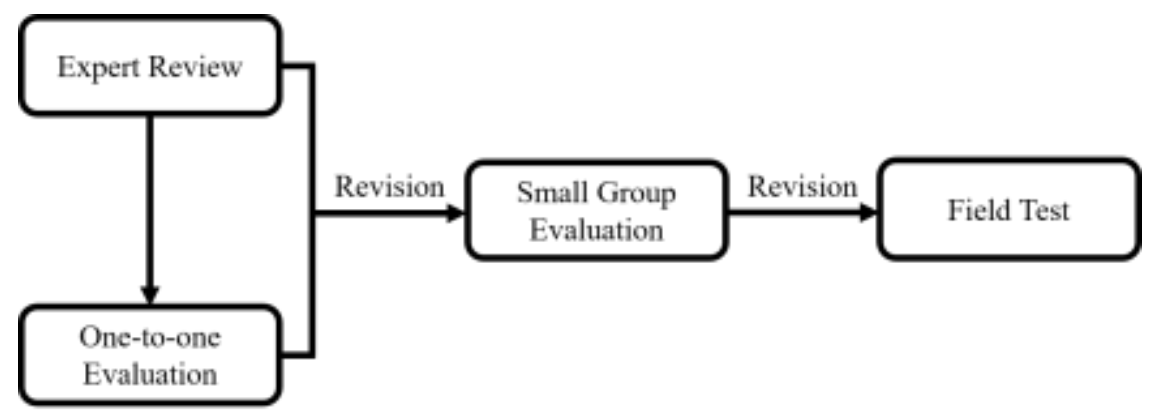

Figure. 1. Formative Evaluation Flow

According to Tessmer [14], the prototype will be tested in several stages of Tessmer's formative evaluation including expert review, one-to-one evaluation, small group evaluation, and field tests. There are 5 learning media experts, 5 learning design experts, and 5 material experts who provide a feasibility assessment using a questionnaire. The one-to-one evaluation phase involved 3 students who had studied mechanical waves, consisting of each student with high, medium, and low ability. Suggestions and criticisms from the expert review and one-toone evaluation stages will be followed up. The revised media will be tested at the small group evaluation stage involving 15 students who have studied mechanical waves, consisting of each 5 high, medium, and low ability students. Criticism and suggestions delivered at this stage are then followed up. The revised media will be tested in the field test involving 30 students who have never studied mechanical waves, consisting of each 10 students of high, medium and low ability.

The assessment of the feasibility of the media by students in the stage of one-to-one evaluation, small group evaluation, and field tests using a questionnaire. While the effectiveness of the media seen from the completeness of student learning outcomes by providing pretest and posttest.

\subsubsection{Summative Evaluation Stage}

The mechanical wave AR learning media is evaluated for its effectiveness by both students and teachers. Fifteen students who have not studied mechanical waves, consisting of high, medium, and low ability students are given a pretest and posttest. Next, the physics teacher was asked to fill in a questionnaire on the effectiveness of the AR-based Android learning media.

\subsubsection{Systematic Reflection and Documentation}

This last stage illustrates all studies to support the analysis, followed by the specification of design principles and connecting them with the conceptual framework [13].

\subsection{Data Analysis Technique}

The results of information from the teacher's interview will be studied and the conclusions taken as a whole. The feasibility of the media is known based on data from the questionnaire results. Questionnaire data obtained is quantitative data, which is translated into 
qualitative data. Five alternative answers are provided on a graded scale ranging from 0 to 4 , which are illustrated in Table 1.

Table 1. Tiered Scale Criteria [15]

\begin{tabular}{cc}
\hline Score & Category \\
\hline 4 & Very feasible \\
\hline 3 & Feasible \\
\hline 2 & Feasible enough \\
\hline 1 & Not feasible \\
\hline 0 & Very not feasible \\
\hline
\end{tabular}

The percentage of answers from each question indicator can be calculated using the following formula [15].

Percentage $=\frac{\sum \text { score of all respondents }}{\sum \text { respondents } \times 4} \times 100 \%$

The effectiveness of the media can be seen from the number of students who get the test results $\geq$ of the KKM (Kriteria Ketuntasan Minimal -criteria for minimum completion) test (75) after learning using Android-based mechanical wave AR media. The effectiveness criteria based on cognitive learning outcomes can be seen in Table 2 below.

Table 2. Effectiveness Criteria based on Cognitive Learning Outcomes

\begin{tabular}{cc}
\hline Score & Category \\
\hline $100 \%$ & Very effective \\
\hline $75 \%$ & Effective \\
\hline $50 \%$ & Effective enough \\
\hline $25 \%$ & Not effective \\
\hline $0 \%$ & Very not effective \\
\hline
\end{tabular}

\section{Discussion and result}

Based on the results of preliminary research obtained information that AR media has advantages as a learning media that can increase student motivation, help students understand the material, and help teachers deliver the material. This supports the achievement of learning objectives and efforts to improve student learning completeness.

The developed mechanical wave AR learning media application is equipped with $3 \mathrm{D}$ animation, audio explanation, material, formulations, sample questions and discussions, video links, simulations, practice questions, based on Android, and using the user define marker method. User defined markers are markers that use patterned objects in the real world that are freely selected by users as markers to display virtual objects on AR media. These markers can be in the form of writing, drawings, patterned cloth, etc., which are patterned.

Through user-defined markers, users can use the AR application without having to have a special marker card. This supports the wider use of AR media. Users are not dependent on the presence of markers, do not need to spend money to print markers, and do not have to worry if the marker is damaged, so it is easier to learn wherever and whenever without using special markers. 
Media that displays 3D objects overcome the weaknesses of 2-dimensional (2D) media because it provides a more tangible and concrete visualization, besides 3D objects attract students' attention to learn the material. Evaluation questions on AR wave media mechanics provide feedback in the form of scores obtained, completeness values, answer keys, and discussion of questions. Feedback is an important part in an evaluation because it is useful for measuring ability and monitoring student learning outcomes.

The feasibility of the media is seen from the assessments given by experts and students, while the effectiveness of the media is seen from the results of student learning at all stages and the teacher's assessment on summative evaluations. The results of the media feasibility assessment can be seen in the Table 3.

Table 3. Media Feasibility Assessment Results

\begin{tabular}{ccccccc}
\hline & $\begin{array}{c}\text { Learning } \\
\text { Media Expert }\end{array}$ & $\begin{array}{c}\text { Learning } \\
\text { Design Expert }\end{array}$ & $\begin{array}{c}\text { Material } \\
\text { Expert }\end{array}$ & $\begin{array}{c}\text { One to One } \\
\text { Evaluation }\end{array}$ & $\begin{array}{c}\text { Small } \\
\text { Group } \\
\text { Evaluation }\end{array}$ & Field Test \\
\hline Score & $94 \%$ & $91 \%$ & $90 \%$ & $96 \%$ & $86 \%$ & $82 \%$ \\
\hline Category & Very feasible & Very feasible & $\begin{array}{c}\text { Very } \\
\text { feasible }\end{array}$ & Very feasible & Feasible & Feasible \\
\hline
\end{tabular}

The application of mechanical wave AR learning media as a whole is declared feasible by five learning media experts. Assessment includes two aspects, namely software engineering and visual communication. The software engineering aspect got $92 \%$ with a very good category. The software engineering aspect consists of 10 assessment indicators, including effective and efficient, reliable, maintainable, usability, accuracy in choosing the type of application, compatibility, package programming, documentation, and reusable. AR media minimizes the cost of education because at one time the cost of making AR media can be spread and used by many Android-based smartphone users. This has become one of the advantages of AR media in saving costs and time compared to props. AR can be developed to replace practicum tools. Users do not need to carry out complex maintenance on the media and easy operation to attract students to use it.

Aspects of visual communication get a percentage of $96 \%$ with a very good category. Aspects of visual communication consist of 7 indicators, including communicative, creative in the following ideas pouring ideas, simple and attractive, audio, visual, mobile media, and interactive layouts. Good visual communication is needed to attract the user's attention so that the purpose of making media is conveyed. Good visual communication is needed to attract the user's attention so that the purpose of making media is conveyed. The availability of narrative explanations that are appropriate to the material and the quality of sounds that can be heard clearly supports the student's process of learning the material. Besides 3D objects can be seen clearly, can be enlarged, and rotated so that it can be seen from various points of view.

The application of mechanical wave AR learning media as a whole was declared feasible by five learning design experts in the aspects of learning design with a total score of $91 \%$ with a very good category. The learning design aspect consists of 16 indicators, namely clarity of learning objectives; relevance of learning objectives with curriculum; scope and depth of learning objectives; the accuracy of the use of learning strategies; interactivity; providing learning motivation; contextually and actuality; completeness and quality of learning assistance materials; the suitability of the material with the learning objectives; material depth; easy to understand; systematic, trace, clear logic flow; clarity of description, discussion, examples, simulations, exercises; consistency of evaluation with learning objectives; the 
accuracy and permanence of the evaluation tools; and providing feedback on the evaluation results. Presentation of appropriate learning materials in accordance with the curriculum helps in achieving learning objectives.

The assessment of AR media by five experts of learning material as a whole was declared feasible with a score of $90 \%$ which was included in the excellent category. Learning material experts conduct assessments on 6 aspects, namely the scope and depth of the material; accuracy of presentation (systematic) on the material; the suitability of the material in 3D images and animation with existing theories; the suitability of narrative explanations on 3D images and animation with existing theories; clarity of sample training questions on each wave material; and the accuracy of the answers to the sample practice questions on each material of mechanical waves.

AR media is considered very feasible by students in one-on-one evaluations with a value of $96 \%$ (very feasible). The feasibility aspects assessed by students at this stage include material aspects, learning design, implementation, and technical quality with the acquisition of the respective percentages of $100 \%, 97 \%, 96 \%$, and 93\%, all in the very good category. According to students, mechanical wave material is difficult to understand, but after using AR the mechanical wave students feel more understanding because the material is delivered clearly, interestingly, and with interactive technology. Text material presented on AR media can be enlarged according to user needs, this has become one of the advantages of developing mechanical wave AR media. Students argue that the use of AR media can be used anywhere and anytime making it easier for them to access information. AR media is easy to use, this is shown with high enthusiasm to students who are able to operate AR independently even though students have not been taught its use.

The feasibility of the media is considered feasible students at the evaluation stage of small groups with a value of $86 \%$ (feasible). The feasibility aspects assessed by students are efficiency, material, learning design, and implementation. Meanwhile, the eligibility of AR media by students in the field test earned a score of $82 \%$ (feasible). The feasibility aspects assessed by students included implement ability, sustainability, appropriateness, as well as acceptance and attractiveness aspects. The advantages possessed by the AR media make it useful to use both now and in the future as a learning aid tool.

The effectiveness of the media can be seen from the completeness of student learning outcomes, students are said to be complete when getting a value more than or equal to a minimum completeness criterion of 75 . Completeness of student learning outcomes after using AR wave learning media can be seen in the Table 4.

Table 4. Completeness of Student Learning Results

\begin{tabular}{cccccc}
\hline & $\begin{array}{c}\text { One to One } \\
\text { Evaluation }\end{array}$ & $\begin{array}{c}\text { Small Group } \\
\text { Evaluation }\end{array}$ & Field Test & $\begin{array}{c}\text { Summative } \\
\text { Evaluation } \\
\text { (Students) }\end{array}$ & $\begin{array}{c}\text { Summative } \\
\text { Evaluation } \\
\text { (Teachers) }\end{array}$ \\
\hline $\begin{array}{c}\text { Mastery of } \\
\text { students in } \\
\text { Pretest }\end{array}$ & $33 \%$ & $13 \%$ & $0 \%$ & $0 \%$ & - \\
\hline $\begin{array}{c}\text { Mastery of } \\
\text { students in } \\
\text { Posttest }\end{array}$ & $\begin{array}{c}67 \% \\
\text { (Effective) }\end{array}$ & $\begin{array}{c}80 \% \\
\text { (Effective) }\end{array}$ & $\begin{array}{c}60 \% \\
\text { (Effective } \\
\text { enough) }\end{array}$ & $\begin{array}{c}73 \% \\
\text { (Effective) }\end{array}$ & $\begin{array}{c}\text { Very } \\
\text { effective) }\end{array}$ \\
\hline
\end{tabular}

Students who are involved in one-to-one evaluation and small group evaluation are students who have studied mechanical waves with their teacher without using AR wave media 
mechanics. While students who are involved in the field test and summative evaluation are students who have never studied mechanical waves before.

Based on the data obtained, students who have or who have never studied mechanical waves have experienced an increase in mastery learning outcomes after learning this material using AR mechanical wave media, this shows that the AR mechanical wave media is effective for increasing mastery learning outcomes of students. Physics teachers in summative evaluation give an assessment through a questionnaire of $94 \%$ (very effective). Assessments conducted by physics teachers consist of indicators of achievement of learning objectives and ease in explaining teaching material.

\section{Conclusion}

The development of AR wave learning media mechanics has fulfilled the feasibility and effectiveness aspects to be used as an alternative media in learning. The conclusions of this development research are as follows:

The AR wave media developed was considered suitable for use in learning. Learning media experts gave a feasibility value of $94 \%$ (very feasible), five learning design experts gave a worthiness of $91 \%$ (very feasible), and five material experts gave a worthiness of $90 \%$ (very feasible). The feasibility assessment by students in the one-on-one evaluation was $96 \%$ (very feasible), in the small group evaluation stage was $86 \%$ (feasible), and in the field test it was $82 \%$ (feasible).

The AR wave media developed was declared effective based on student learning outcomes and teacher questionnaire responses. The one-on-one evaluation stage gained $67 \%$ completeness (effective). The small group evaluation stage gets $80 \%$ completeness (effective). The field test phase gained $60 \%$ completeness (quite effective). The summative evaluation stage gained $73 \%$ completeness (effective). The assessment of effectiveness by 4 physics teachers was $94 \%$ (very effective).

\section{REFERENCES}

[1] Aleksandrov, Evgeny and Anastasia Levitskaya. (2018). Technology of Integrated Media Education. Media Education (Mediaobrazovanie). 58 (4).

[2] Sannikov, Sergey, et. al. (2015). Interactive Educational Content Based on Augmented Reality and 3D Visualization, Procedia Computer Science, Elsevier. Vol. 66.

[3] Bond, Melissa, Victoria I. Marin, Carina Dolch, Svenja Bedenlier and Olaf ZawackiRichter. (2018). Digital Transformation in German Higher Education: Student and Teacher Perceptions and Usage of Digital Media. 15:48.

[4] Huang, Kuo-Ting, Christopher Ball, Jessica Francis, and Rabindra Ratan. (2019) Augmented Versus Versus Virtual Reality in Education: an Exploratory Study Examining Science Knowledge Retention when Using Augmented Reality/Virtual Reality Mobile Application. Cyberpsychology, Behavior, and Social Networking. Vol. 22, No. 2.

[5] Molnár, György and András Benedek. (2015). Three Dimensional Application in Teaching and Learning Process. Procedia Social and Behavioral Sciences Elsevier.

[6] Pohlmann, Mariana and Fabio Pinto da Silva. (2019). Virtual and Augmented Reality in Learning Objects: a Case Study for Technical Drawing Teaching. International Journal of Education and Research. Vol. 7, No. 1. 
[7] Lopez, David Perez and Manuel Contero. (2013). Delivering Educational Multimedia Contents through an Augmented Reality Application: A Case Study on its Impact on Knowledge Acquisition and Retention. The Turkish Online Journal of Educational Technology. Vol. 12.

[8] Saidin, Nor Farhah, et. al. (2015). Review of Research on Augmented Reality in Education: Advantages and Applications. International Education Studies Published by Canadian Center of Science and Education. Vol. 8. No. 13.

[9] Cai, Su, et. al. (2013). Using the Augmented Reality 3D Technique for a Convex Imaging Experiment in a Physics Course. International Journal of Engineering Education. Vol. 29. No. 4.

[10] Nguyen, Nguyen, et. al. (2018) An Interactive and Augmented Learning Concept for Orientation Week in Higher Education. International Journal of Educational Technology in Higher Education.

[11] Almenara, Julio Cabero, Jose Maria Fernandez-Batanero, and Julio Barroso-Osuna. (2019) Adoption of Augmented Reality Technology by University Students. Heliyon.

[12] Barniol, Pablo and Genaro Zavala. (2017). The Mechanical Waves Conceptual Survey: An Analysis of University Students' Performance, and Recommendations for Instruction. EURASIA Journal of Mathematics Science and Technology Education. 13 (3).

[13] Akker, Jan van den, et. al. (2006). Educational Design Research. New York: Routledge.

[14] Tessmer, Martin. (1993). Planning and Conducting Formative Evaluations. London: Routledge.

[15] Sugiyono. (2016). Metode Penelitian Kuantitatif Kualitatif dan $R$ \& D. Bandung: Alfabeta. 